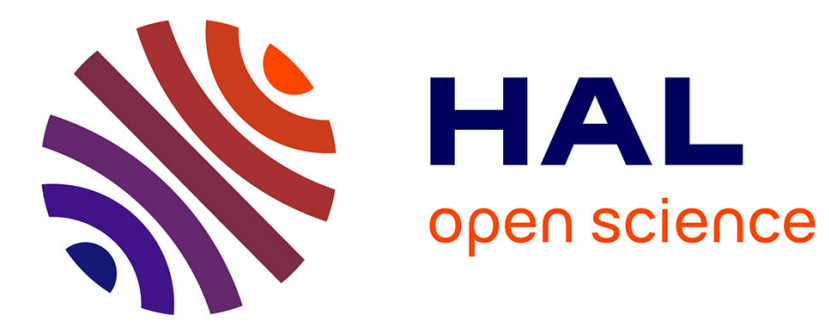

\title{
Sintering of aerogels for glass synthesis
}

\author{
Thierry Woignier, Michel Prassas, Laurent Duffours
}

\section{To cite this version:}

Thierry Woignier, Michel Prassas, Laurent Duffours. Sintering of aerogels for glass synthesis. Journal of Sol-Gel Science and Technology, 2019, 90, pp.76-86. 10.1007/s10971-018-4826-4 . hal-02464315

\section{HAL Id: hal-02464315 \\ https://hal.science/hal-02464315}

Submitted on 3 Feb 2020

HAL is a multi-disciplinary open access archive for the deposit and dissemination of scientific research documents, whether they are published or not. The documents may come from teaching and research institutions in France or abroad, or from public or private research centers.
L'archive ouverte pluridisciplinaire HAL, est destinée au dépôt et à la diffusion de documents scientifiques de niveau recherche, publiés ou non, émanant des établissements d'enseignement et de recherche français ou étrangers, des laboratoires publics ou privés. 


\title{
Sintering of aerogels for glass synthesis
}

\author{
Thierry Woignier ${ }^{1,2} \cdot$ Michel Prassas $^{3} \cdot$ Laurent Duffours $^{4}$
}

\begin{abstract}
Silica glasses can be synthesized by sintering silica aerogels at temperatures ranging from 900 to $1200^{\circ} \mathrm{C}$, i.e., close to half the temperatures used for glass melting. The heat treatment can be tailored to obtain either fully densified or porous glass. This paper describes the different steps of the transformation of aerogels into glass along with the textural and microstructural transformations. Different types of information are analyzed: variations in dimensional shrinkage and the apparent density as a function of the densification conditions (temperature, duration of the thermal treatment), the associated structural changes, and the changes in the porous characteristics (macro and meso porosity, average pore radius). The kinetics of dimensional shrinkage help characterize the sintering mechanism. Structural data and porous characteristics allowed us to quantify the transformation of internal aggregates and porosity.
\end{abstract}

\section{Graphical Abstract}

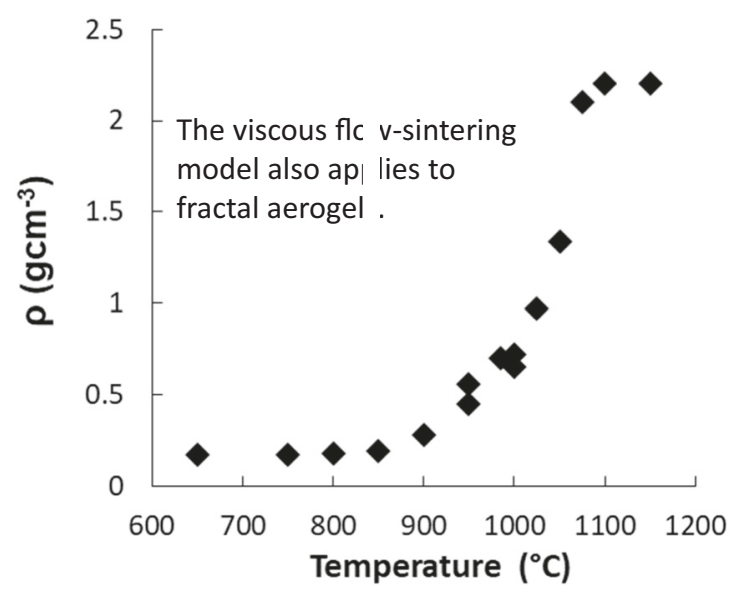

\section{Highlights}

- The viscous flow sintering model proposed by Scherer is in good agreement with the sintering kinetics of fractal aerogels.

- The viscosities of aerogels and the activation energies of the sintering process depends on the $\mathrm{OH}$ content.

- The size of the aggregates decreases and the particles increase in size, fractal dimension tends to 3 .

- The smaller pores sinter first, this local densification causes narrowing of the macropores.

Key words Silica aerogel $\cdot$ Sintering $\cdot$ SAXS $\cdot$ Fractals $\cdot$ Viscosity $\cdot$ Pore size distribution

Thierry Woignier

thierry.woignier@imbe.fr

1 Aix Marseille Univ, Univ Avignon, CNRS, IRD, IMBE, Marseille, France
2 IRD UMR 237-Campus Agro Environnemental Caraïbes-B.P. 214 Petit Morne, 97232 Le Lamentin, Martinique

3 Corning European Technology Center, 77210 Avon, France

4 Prime Verre, 34090 Montpellier, France 


\section{Introduction}

The physical and chemical properties of glasses have been widely analyzed and their applications are well known [1, 2]. Glasses are used as optical materials and containers, but also for specific applications (reinforcement fibers, storage of nuclear waste,...). Ordinary glass (window glass and other silicates) are usually made in several steps: different oxides are mixed at high temperature, followed by a refining step and quenching; the last step causes the freezing of the amorphous structure of the melt. In the early 1980s, a new process was proposed: glasses are no longer prepared using the conventional melting and refining processes, but instead the sol-gel method [3, 4]. Since the silica gel is amorphous, it can be converted into silica glass at low temperature by "sintering" i.e., without melting or refining. Sintering is a densification heat treatment needed to convert highly porous silica gels into glass without porosity [3]. The sintering treatment is carried out at temperatures one-third to one-half lower than those required to melt the vitrifying compounds, almost the same as the glass transition temperature. Reports in the literature show that the sintering process makes it possible to progressively eliminate the porous structure of the aerogel until complete densification is achieved, resulting in a silica glass [5-8]).

Silica aerogels are characterized by high porosity, and this large pore volume can be used as host matrix for the synthesis of different types of materials including multicomponent aerogels, binary glasses, composites, or even materials with gradient properties [9-11]. For this purpose, certain physical properties that depend on the porosity of the aerogel (permeability, diffusion, and mechanical properties) are important. Hence, porosity characteristics and the microstructure of the solid network, such as pore volume, density, and pore size distribution, need to be controlled.

In this paper, we report sintering experiments realized on silica aerogels. We analyzed the sintering of fractal aerogels in order to confirm whether the Scherer flow-sintering model $[7,12]$ also applies to fractal aerogels.

\section{Experimental section}

\subsection{Synthesis of materials}

The silica gels selected in this study were made from tetramethoxysilane (TMOS) hydrolyzed in neutral (distilled water) or basic (10-2 M, NH4OH) conditions. The ethanol $/ \mathrm{H}_{2} \mathrm{O}$ mixture was stirred and aged for 1 week at room temperature. The volume fraction of the solid was adjusted from the organosiloxane content diluted in the original solution ( $26-46 \%$ by volume). The gels were transformed into aerogels by supercritical drying at $305^{\circ}$ $\mathrm{C}$ and $13 \mathrm{MPa}$ [5]. The aerogels are labeled $\mathrm{Ny}$ and $\mathrm{By}$, where $\mathrm{y}$ is the TMOS content, N and B are neutral or basic conditions, respectively. The aerogels have hydrophobic properties immediately after drying. Heat treatment at $350^{\circ} \mathrm{C}$ for $12 \mathrm{~h}$ makes it possible to eliminate their surface organic radicals.

\subsection{Densification procedure}

Sintering was characterized in dilatometer experiments in the temperature range $25-1300^{\circ} \mathrm{C}$. Sintering of silica aerogels, which proceeds by viscous flow at high temperature, has been previously described [5-8]. Depending on the duration of the heat treatment, the pores collapse and the apparent density increases up to the density of the silica glass $2.2 \mathrm{~g} \mathrm{~cm}^{-3}$. In this study, sintered aerogel samples covered a density range of $0.17-2.2 \mathrm{~g} \mathrm{~cm}^{-3}$ (porosity between $98 \%$ and $0 \%$ ).

\subsection{Structural characterization}

\subsubsection{Small-angle X-ray scattering}

The aerogel structure was characterized using small-angle scattering techniques. Scattering vectors $\mathrm{q}$ ranging from 0.0018 to $0.3 \AA^{-1}$ were explored, making it possible to determine the density-density correlation function in a length scale of from 3 to $500 \AA$. Small-angle X-ray scattering (SAXS) provides information on the structure and degree of compaction in the aggregates forming the aerogel network [13, 14]. Analyzed in terms of fractal geometry $[15,16]$, the experiments provided three characteristic information elements about structure: the average size of the fractal aggregates $(\xi)$, the average size of the primary particles $(a)$ that stick together to form the aggregates, and the fractal dimension $D$, which expresses the compactness of the aggregates. The power law portion, which appears to be linear in a logarithmic scale, has a slope related to $-D$. The position of the two changes in slope is, respectively, related to the inverse of the size of the cluster $(\xi)$ and of the size of the particles $(a)$. To analyze the data, the SAXS curves can be fitted using the following relation:

$$
\mathrm{I}(\mathrm{Q})=\mathrm{A} \rho^{2} \xi^{2} \frac{\Gamma(D+1)}{\left(1+\mathrm{q}^{2} \xi^{2}\right)^{(D-1) / 2}} \frac{\sin (D-1) \arctan (\mathrm{q} \xi)}{(D-1) \mathrm{q} \xi}
$$

where $\Gamma(\mathrm{x})$ is the mathematical gamma function and $\mathrm{A}$ is a constant of normalization. This expression describes both the Guinier and fractal regimes, as well as crossovers between the two regimes $[15,16]$. 


\subsubsection{Raman scattering}

The vibrational properties of silica aerogels were studied using low-frequency Raman spectrometry in a frequency range of $6-60 \mathrm{~cm}^{-1}$. The $I(\omega)$ spectra were obtained with a classical Raman scattering system. The $514.5 \mathrm{~nm}$ or $488 \mathrm{~nm}$ line of an argon ion laser was used, with an incident output power of $400 \mathrm{~mW}$. The width of the spectral slit was set at $1 \mathrm{~cm}^{-1}$. A triple monochromator spectrometer was used to analyze the scattered light [16]. The main characteristic of low-frequency Raman spectra is a characteristic peak related to the vibrational mode of the constituent particles. Assuming that the structural units are spherical particles, it has been shown that the frequency $\omega_{\mathrm{p}}$, of the peak, is correlated with the diameter a of the particle by: $\omega_{\mathrm{p}} / 2 \pi=\mathrm{Z} / \mathrm{a}$ where $\mathrm{Z}$ is a parameter dependent on the transverse sound velocity $[17,18]$.

\subsection{Porous characteristics}

The density was determined by the weight and dimensions of the samples and we calculated the porosity and total pore volume from the bulk density and skeletal density $(2 \mathrm{~g} \mathrm{~cm}$ ${ }^{-3}$ ) [19]. The different pore size ranges were defined as: micropores (0-2 nm); mesopores (1-40 nm); and macropores $(>40 \mathrm{~nm})$. We measured the mesoporous characteristics (pore size, pore volume, and pore size distribution) by thermoporometry. Thermoporometry is a thermal method that analyzes the conditions of solidification of a condensate that saturates the porous material. The experimental setup is described elsewhere [20]. We impregnated the aerogels with water by inverse hypercritical drying according to a previously described procedure [21]. Previous data showed that aerogels have no microporous volume [21] and we calculated the macroporous volume by subtracting the mesoporous volume measured by thermoporometry from the total pore volume.

\section{Results and discussion}

\subsection{Sintering of aerogels}

Aerogels are macroscopically very different from silica glasses; however, Raman, infrared, and NMR spectroscopy used to characterize the molecular structure have identical signatures to those observed in vitreous silica [5, 10]. These types of porous materials can be considered as porous glasses, even though they differ greatly in how they reach the "vitreous" state. The sintering step should make it possible to convert this porous and partially organic material into dense silica while avoiding crystallization. Aerogels are made of amorphous silica, like glass, the main differences being the high porosity and the high concentrations of hydroxyl and organic groups in the aerogels. Heat treatments eliminate unwanted chemical species and pores. The thermograms obtained by differential thermal analysis (DTA), thermogravimetry, and dilatometry show three temperature ranges related to the changes in the aerogel features. The endothermic DTA bands in the 25$200{ }^{\circ} \mathrm{C}$ range are due to the vaporization of water and alcohol. Exotherms in the $250-500^{\circ} \mathrm{C}$ range were attributed to the oxidation of organic species [5, 10]. Structural changes in silica aerogels were previously [5] monitored as a function of temperature using transmission IR spectroscopy. At low temperatures, the IR spectra indicate that $\mathrm{O}$ $\mathrm{CH}_{3}$ or $\mathrm{O}-\mathrm{C}_{2} \mathrm{H}_{5}$ groups resulting from gelation react with oxygen. The oxidation reaction starts at about $250{ }^{\circ} \mathrm{C}$ and is complete at $500{ }^{\circ} \mathrm{C}$. The IR spectra also show that the adsorbed water disappears at low temperatures; however, the IR spectra of aerogels treated at $900{ }^{\circ} \mathrm{C}$ show the presence of $\mathrm{OH}$ groups remaining in the structure (stretching vibration band at $3660 \mathrm{~cm}^{-1}$ ).

The dilatometry data showed that the sintering densification started in the temperature range $\left(500-1000^{\circ} \mathrm{C}\right)$ and that it increased rapidly around $1000^{\circ} \mathrm{C}$ [22], a temperature much lower than the melting temperature of quartz $\left(1610^{\circ}\right.$ C). Figure 1 shows the sintering measurements made at several temperatures in the range $650-1150{ }^{\circ} \mathrm{C}$ (over a period of $2 \mathrm{~h}$ ). The data reveal a sharp increase in density with temperature. In the temperature range $1050-1075^{\circ} \mathrm{C}$, the pore volume was completely be removed and the bulk density was close to $2.2 \mathrm{~g} \mathrm{~cm}^{-3}$, the density of silica glass.

Sintering is a process by which the surface of a material is reduced by mass transport [12, 22-24]. In a previous work [22], we showed that two types of mechanisms are responsible for sintering. At low temperatures $\left(500-700{ }^{\circ} \mathrm{C}\right)$, sintering is due to a diffusion

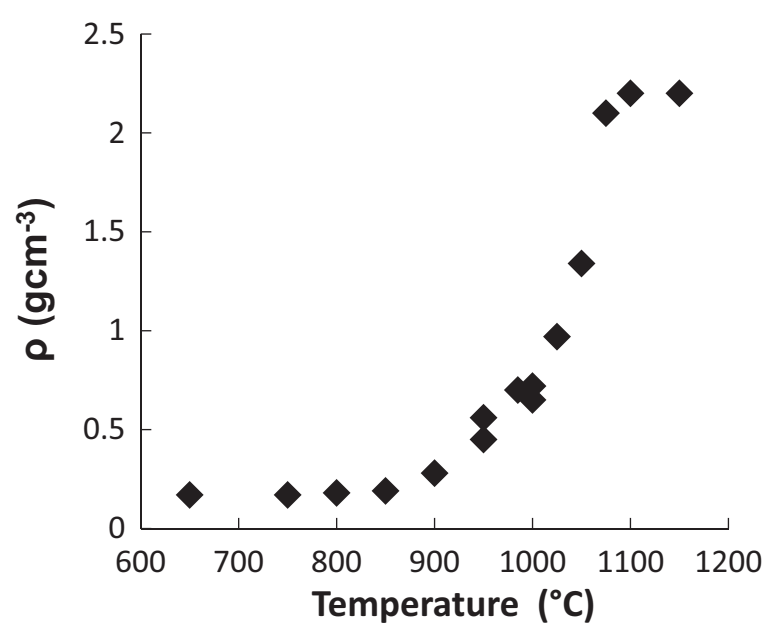

Fig. 1 Apparent density as a function of the temperature of the heat treatment $(2 \mathrm{~h})$ 
process, whereas at temperatures above $1000{ }^{\circ} \mathrm{C}$, sintering is related to a viscous flow phenomenon with an activation energy of $88 \mathrm{kcal} \mathrm{mol}^{-1}$. In the intermediate temperature range, both processes exist and overlap. The viscous flow mechanism and the determination of its activation energy were identified based on the Frenkel model [24]. However, because of the approximations concerning its geometry, the Frenkel model should not be used after first stages of sintering. For amorphous materials, viscous flow is important because it is much faster than the densification process resulting from diffusion.

Scherer [7, 12] proposed a model describing sintering over a wide range of porosity $(0-95 \%)$. In this model, the relative density $\rho / \rho_{\mathrm{s}}$, where $\rho$ is the bulk density and $\rho_{\mathrm{s}}$ the skeletal density, is plotted against a reduced time $\mathrm{K}\left(t-t_{0}\right), t$ is the sintering time, $t_{0}$ is a fictitious time, and $\mathrm{K}$ is a constant at a given temperature:

$\mathrm{K}=\gamma / \eta \ell_{\mathrm{i}}\left(\rho_{\mathrm{s}} / \rho_{\mathrm{i}}\right)^{1 / 3}$

where $\gamma$ is the surface energy, $\eta$ the viscosity, $\ell_{\mathrm{i}}$ and $\rho_{\mathrm{i}}$ denote the length of the Scherer cell and the initial apparent density of the aerogel, respectively.

$\mathrm{P}_{\mathrm{i}} / \rho_{\mathrm{s}}=3 \pi\left(a / \ell_{\mathrm{i}}\right)^{2}-8 \sqrt{ } 2 a^{3}$

and

$S=1 / a \rho_{\mathrm{s}}\left(6 \pi \ell_{\mathrm{i}}-24 \sqrt{ } 2 a\right) /\left(3 \pi \ell_{\mathrm{i}}-8 \sqrt{ } 2 a\right)$

Sintering was identified by studying the kinetics of shrinkage. The samples were treated isothermally, the apparent density was measured as a function of time, and the relative density was adjusted to the theoretical curve (Fig. 2). This procedure was used to determine the reduced time. If the model applies, the graph of reduced time versus real time will have to be straight lines. We calculated the viscosity at the temperatures of interest from the slopes of the straight lines.

As an example, Fig. 3 shows changes in density as a function of time for aerogel N46 at two different temperatures. Figure 4 shows the deduced lines $\mathrm{K}\left(t-t_{0}\right)$ versus $t$ obtained at the two temperatures.

These results confirm the previous data [5]: sintering occurs by viscous flow and the isothermal densification kinetics of the aerogels corresponds to the Scherer model.

Next, we analyzed the sintering of different aerogels (N40, N33, N26, and B26) to check if the Scherer model applies to aerogels with well-established fractal characteristics such as N33, N26, and B26. For some samples, we monitored the sintering process at different temperatures as a function of time, which enabled us to calculate the activation energy of the sintering process. Table 1 lists the

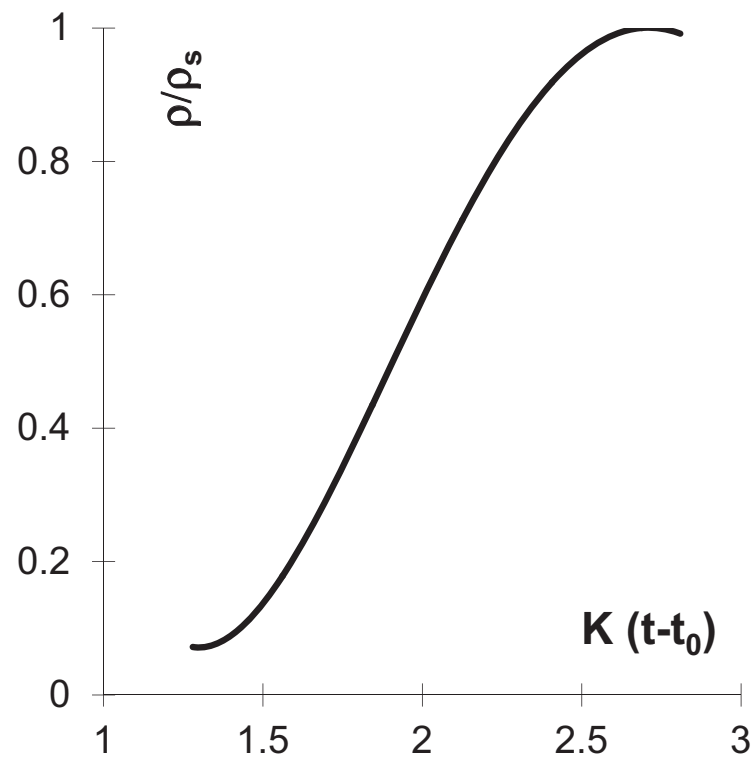

Fig. 2 Theoretical curve of the Scherer model

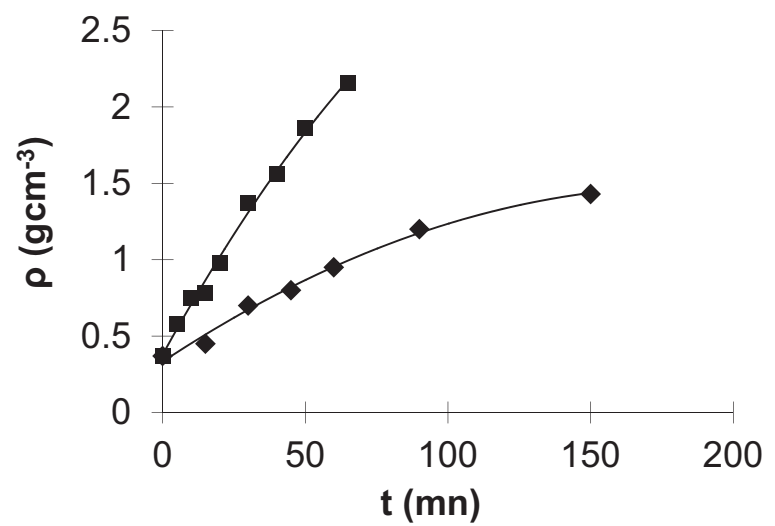

Fig. 3 Bulk density of N46 aerogel versus time at two temperatures $1040{ }^{\circ} \mathrm{C}(\square)$ and $980{ }^{\circ} \mathrm{C}(\diamond)$

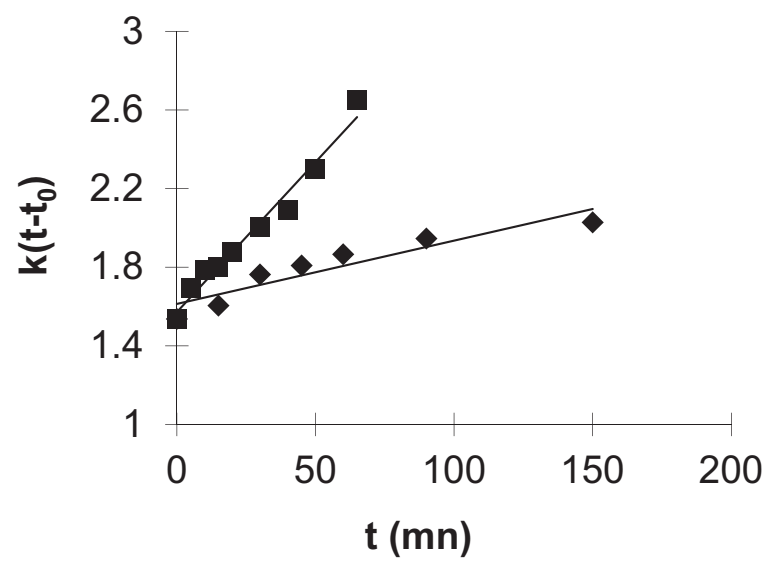

Fig. 4 Plot of $\mathrm{K}\left(t-t_{0}\right)$ of aerogel N46 versus time at two temperatures $1040{ }^{\circ} \mathrm{C}(\square)$ and $980{ }^{\circ} \mathrm{C}($ 
Table 1 Structural and textural characteristics of aerogels

\begin{tabular}{llllll}
\hline Aerogel & Bulk density (g & Specific surface area & $D$ & $\xi(\AA)$ & $a(\AA)$
\end{tabular} $\left.\mathrm{cm}^{-3}\right) \quad\left(\mathrm{m}^{2} \mathrm{~g}^{-1}\right)$

\begin{tabular}{llllll}
\hline $\mathrm{N} 46$ & 0.37 & 410 & 2.4 & 65 & 6 \\
$\mathrm{~N} 40$ & 0.32 & 250 & 2.35 & 80 & 7 \\
$\mathrm{~N} 33$ & 0.23 & 320 & 2.4 & 125 & 6 \\
$\mathrm{~N} 26$ & 0.18 & 300 & 2.35 & 195 & 6 \\
$\mathrm{~B} 26$ & 0.17 & 320 & 1.8 & 50 & 15 \\
\hline
\end{tabular}

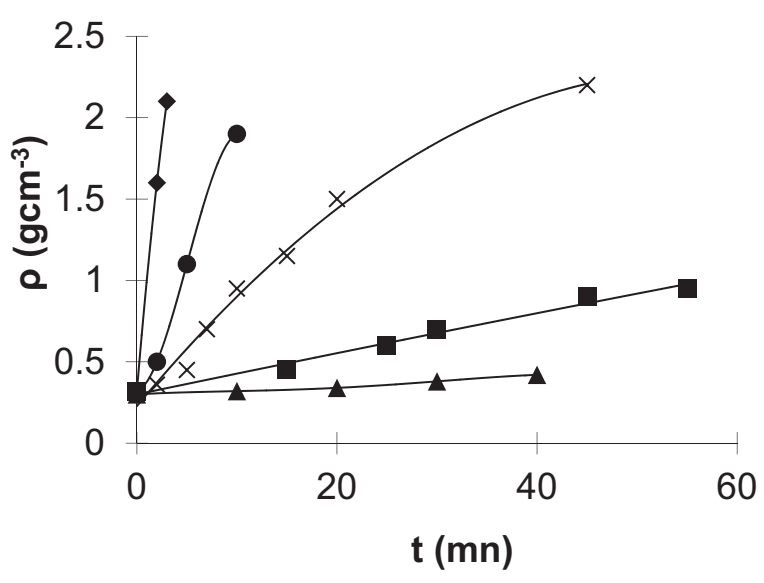

Fig. 5 Plot of $\rho$ as a function of time $(\mathbf{\Delta}) 1005^{\circ} \mathrm{C},(\square) 1050{ }^{\circ} \mathrm{C},(\mathrm{X})$ $1100{ }^{\circ} \mathrm{C}$, (- $1200^{\circ} \mathrm{C}$, and $(\diamond) 1250^{\circ} \mathrm{C}$ (sample N40)

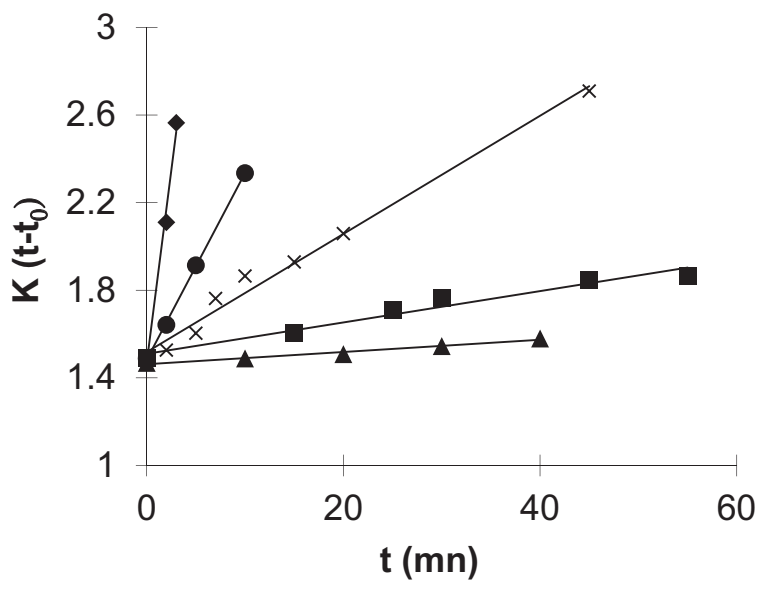

Fig. 6 Plot of reduced time versus $t(\boldsymbol{\Delta}) 1005^{\circ} \mathrm{C},(\boldsymbol{\square}) 1050{ }^{\circ} \mathrm{C},(\mathrm{X})$ $1100{ }^{\circ} \mathrm{C}$, (- $1200{ }^{\circ} \mathrm{C}$, and $(\diamond) 1250{ }^{\circ} \mathrm{C}$ (sample N40)

textural and fractal characteristics of the different aerogels studied in this work.

\subsection{Sintering curves and model extrapolation}

Figures 5-10 show the sintering results (bulk density and reduced time) as a function of time for samples of different aerogels. The data show that in the different samples

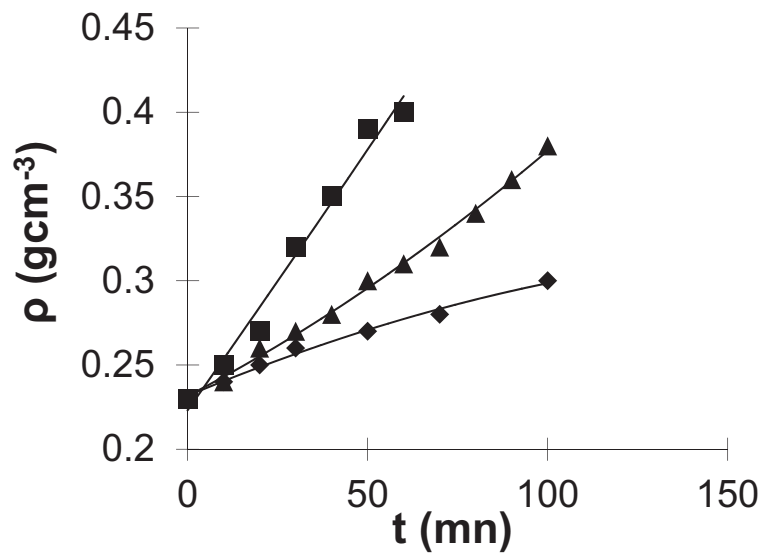

Fig. 7 Plot of $\rho$ as a function of time $(\diamond) 890^{\circ} \mathrm{C},(\boldsymbol{\Delta}) 980^{\circ} \mathrm{C}$, and $1010{ }^{\circ} \mathrm{C}$ (sample N33)

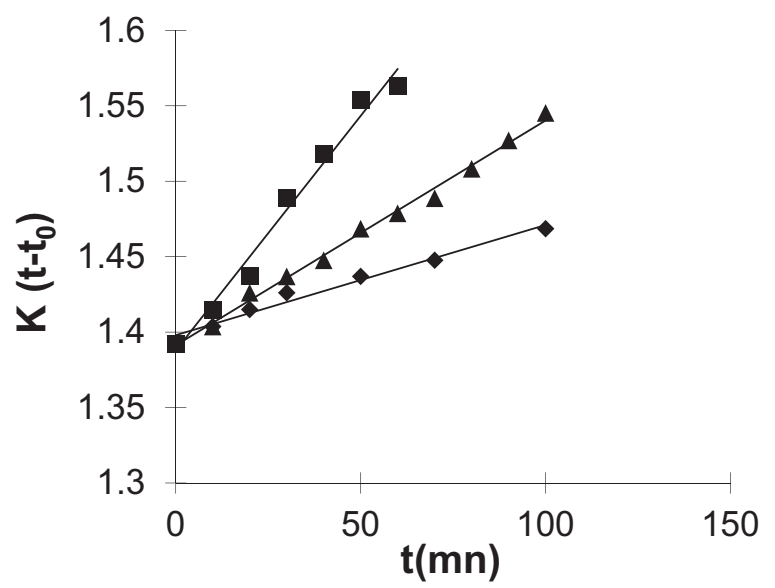

Fig. 8 Plot of $\mathrm{K}\left(t-t_{0}\right)$ versus $t(\bullet) 890^{\circ} \mathrm{C},(\boldsymbol{\Delta}) 980^{\circ} \mathrm{C}$, and (口) 1010 ${ }^{\circ} \mathrm{C}$ (sample N33)

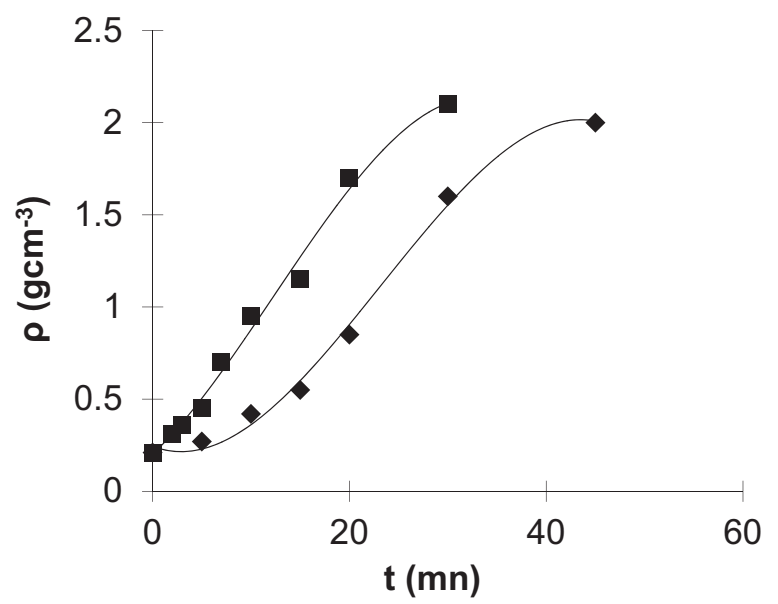

Fig. 9 Plot of $\rho$ as a function of time $(\square) 1150{ }^{\circ} \mathrm{C}$ and $(\bullet) 1100{ }^{\circ} \mathrm{C}$ (sample B26)

studied, sintering occurs by viscous flow and corresponds to the Scherer model. 


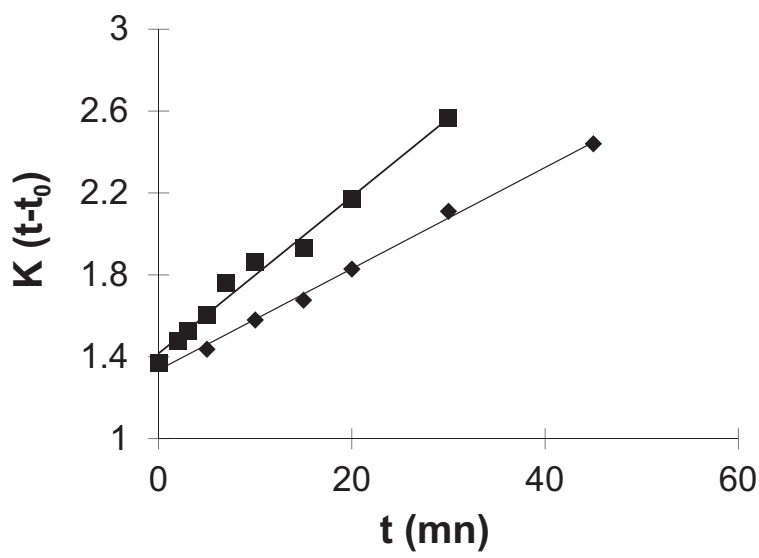

Fig. 10 Plot of $\mathrm{K}\left(t-t_{0}\right)$ versus $t$ for the sample B26: (ם) $1150{ }^{\circ} \mathrm{C}$ and (») $1100{ }^{\circ} \mathrm{C}$

Table 2 Viscosity and activation energy for the studied aerogels

\begin{tabular}{llll}
\hline Aerogel & Temperature $\left({ }^{\circ} \mathrm{C}\right)$ & $\begin{array}{l}\text { Viscosity } \\
\text { poises })\end{array}$ & $\begin{array}{l}\text { Activation energy } \\
\left(\mathrm{kcal} \mathrm{mol}^{-1}\right)\end{array}$ \\
\hline $\mathrm{N} 46$ & 1040 & 13.4 & 90 \\
$\mathrm{~N} 46$ & 980 & 72 & 77 \\
$\mathrm{~N} 40$ & 1250 & 0.5 & \\
$\mathrm{~N} 40$ & 1200 & 2.75 & \\
$\mathrm{~N} 40$ & 1100 & 9.7 & \\
$\mathrm{~N} 40$ & 1050 & 52 & \\
$\mathrm{~N} 40$ & 1005 & 85 & 31 \\
$\mathrm{~N} 40$ & 980 & 192 & \\
$\mathrm{~N} 33$ & 1005 & 82 & Not calculated \\
N33 & 980 & 197 & 38 \\
$\mathrm{~N} 33$ & 900 & 295 & \\
$\mathrm{~N} 26$ & 950 & 291 & 10 \\
$\mathrm{~B} 26$ & 1100 & 7.4 & \\
$\mathrm{~B} 26$ & 1150 & & \\
\hline
\end{tabular}

We observed the same kind of curves for sample N26 (data not shown for simplicity). The good quality of the fit to the Scherer model shows that viscosity does not vary during sintering. Thus, the hydroxyl content remains constant over time, as observed from isothermal thermogravimetric measurements [5]. 3.3 Viscosity and activation energy. The viscosities (Table 2) are calculated by the relation (2). Using the surface energy of the silica (280 erg $\mathrm{cm}^{-2}$ ), the value $\mathrm{li}$ is deduced from the initial relative density and the specific surface area, using the relations (3) and (4) of the Scherer model [12]. (cf paragrapph 3.1)

The viscosity values are close to those expected in such materials. The calculated activation energies $(90-30 \mathrm{kcal}$ $\mathrm{mol}^{-1}$ ) agree quite well with the previously obtained value $\left(88 \mathrm{kcal} \mathrm{mol}^{-1}\right)$ [22]. The activation energy of the viscosity of silica glass has been calculated in the literature [25]. The authors showed that viscosity and activation energy depend

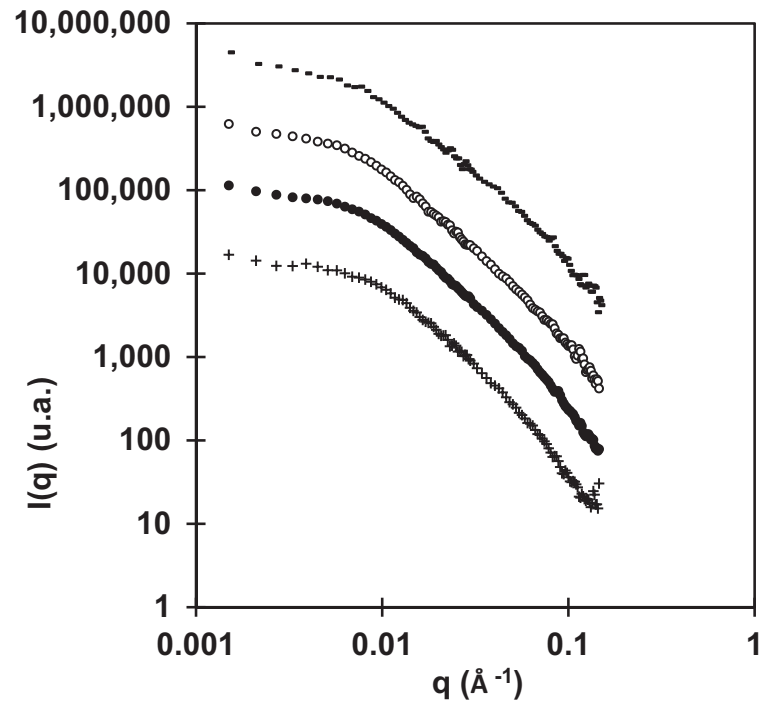

Fig. 11 Variations in scattering data in sintered samples with $\rho=0.17$ $(-), 0.22(\mathrm{O}), 0.32(\bullet)$, and $0.64(+)$ (sintering of N26)

on the $\mathrm{OH}$ glass content [25]. $\mathrm{OH}$ acts as a modifier of glass structure (such as sodium) decreasing glass connectivity and therefore reducing its viscosity [26].

In the case of vitreous silica, values ranging from 120 to $170 \mathrm{kcal} \mathrm{mol}^{-1}$ were measured for a hydroxyl content ranging between 1300 and $3 \mathrm{ppm}$. Our results are in agreement with those mentioned above if we consider the high $\mathrm{OH}$ content of aerogel samples. The $\mathrm{OH}$ concentration varied between 3000 and $5000 \mathrm{ppm}$ [5].

\section{Changes in fractal structure during sintering}

\subsection{Scattering techniques}

Scattering techniques (SAXS) provide information on the structure and degree of compaction in the clusters that form the aerogel network. The main datum that we can infer from the diffusion curves is the fractal dimension $D$ that is related to the mass distribution in the cluster. We calculate $D$ from the slope of the linear part and estimate the size of the fractal cluster $(\xi)$ and the elementary particles $(a)$ that build the cluster from the bounds of the linear part $[27,28]$. The aerogel network can be described as an aggregate assembly $(\sim 50-200 \mathrm{~nm})$. Aggregates can be fractal $(D=1.8-2.4)$, constructed by the aggregation of small particles $(1-2 \mathrm{~nm})$ [28]. The porosity is completely open and covers the range of meso- and macroporosity [29].

Figure 11 shows typical variations in scattering intensity $\mathrm{I}(\mathrm{q})$ as a function of the wave vector q during the sintering of sample N26. As densification continues, the scattered intensity data reveal changes in the aerogel structure. From 


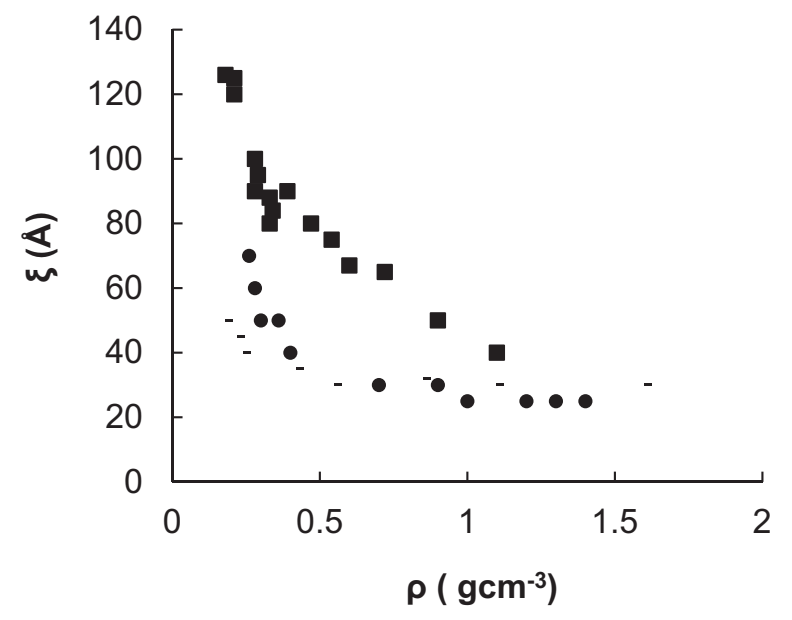

Fig. 12 Changes in $\xi$ the bulk density of samples N26 ( $\square$ ), N33 ( and B26 (-)

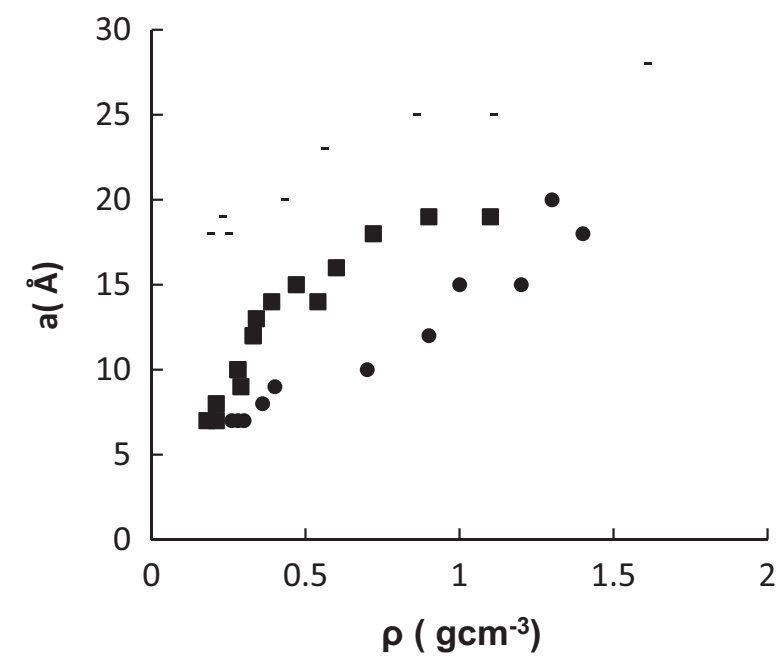

Fig. 13 Changes in a versus the bulk density for the samples N26 ( $\mathrm{N} 33(\mathbf{)})$, and B26 (-)

these curves, we calculated the different characteristics $D, \xi$, and $a$ for samples N26, N30, and B26 (Figs 12-14). The size of the aggregates decreases and the particles increase in size. $D$ appears to remain constant in the initial stages of sintering and then tends to 3 [30]. These transformations indicate the rearrangement of clusters toward greater compactness. Our interpretation of the scattering data suggests that densification induced by viscous flow tends to contract the aggregates and consequently reduce the volume of the sample. Densification occurred through coalescence of small particles into larger ones. $D$ tends to 3 , indicating an internal densification of the aggregates related to the coalescence of the particles. Local sintering has two effects: it pulls on the network, shrinks the cluster, and increases connectivity across the material as a whole.

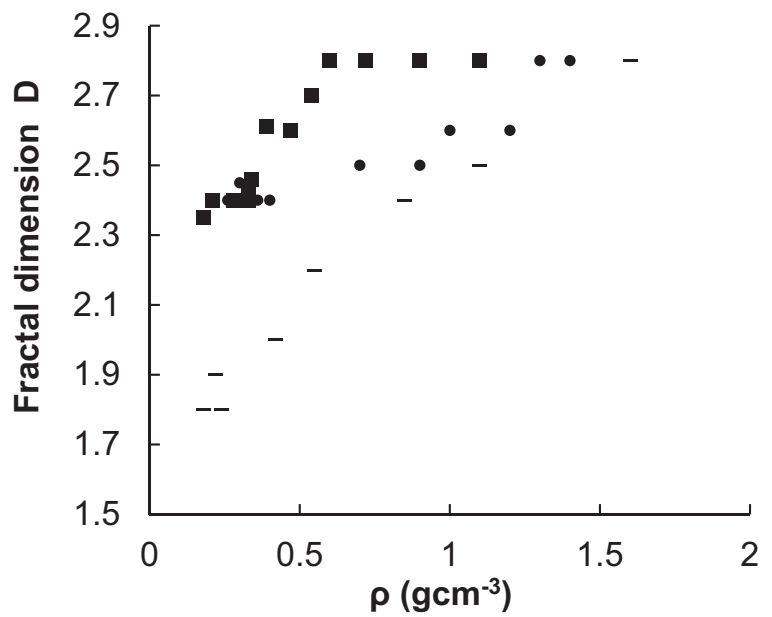

Fig. 14 Variations in D versus the bulk density of samples N26 ( $\square$ ), $\mathrm{N} 33(-)$ and B26 (-)

Figures 12, 13, and 14 show that although the structure of aerogels N26, N33, and B26 is clearly different at the beginning of the sintering process, the three samples tend to homogenize in the density range $0.8-1.2 \mathrm{~g} \mathrm{~cm}^{-3}(50 \%$ porosity). $D, \xi$, and $a$ tend toward close values: $D=2.7-$ $2.8, \xi=30-40 \AA$, and $a=20-25 \AA$. It should be noted that for a bulk density higher than $1.2 \mathrm{~g} \mathrm{~cm}^{-3}$, the description in terms of fractal structure is questionable because the fractal range $\xi / a$ is low, and $\xi$ and $a$ are close.

\subsection{Raman scattering}

We studied the vibrational properties of silica aerogels using low-frequency Raman spectrometry. Raman scattering occurred in partial propagation mode (acoustic type modes) and non-propagative mode of vibration (surface mode). At frequencies above $10 \mathrm{~cm}^{-1}$, there was a particular characteristic in the Raman spectrum: a peak in the range 7 $30 \mathrm{~cm}^{-1}$ [17]. In the literature $[17,18]$ it has been proposed that the frequency of this peak is linked to the vibrational mode of the constituent particles of the materials, and that the wave number $\left(\omega_{\mathrm{p}}\right)$ of the peak is inversely proportional to the particle size. The observation of such a peak was first described in nucleated cordierite glass, but also in aerogels [18]. Here we report our study in a frequency range of 6-60 $\mathrm{cm}^{-1}$, in which we analyzed the position of this peak as a function of the modifications induced by the heat treatment leading to aerogel densification [31]. Figure 15 shows changes in $\omega_{\mathrm{p}}$ with respect to density for samples N26 and B26. The data are in good agreement with those deduced from SAXS experiments in similar samples (see Fig. 13). The basic aerogel is constructed of particles larger than the neutral aerogels $\left(\omega_{\mathrm{p}}\right.$ is $15 \mathrm{~cm}^{-1}$ instead of $\left.30 \mathrm{~cm}^{-1}\right)$. The densification process was accompanied by a shift of the peak toward the low frequencies. At the highest densities, 


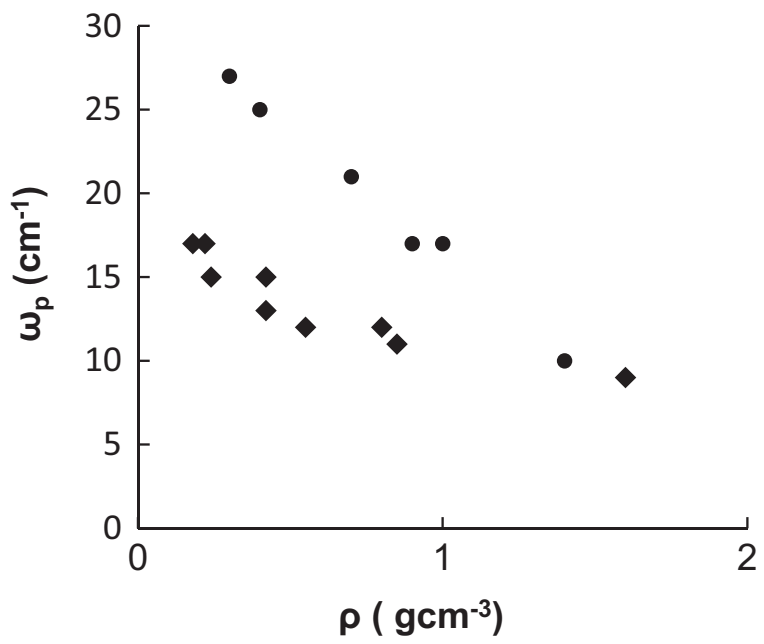

Fig. 15 Variations in $\omega_{\mathrm{p}}$ with respect to the bulk density of samples B26 ( $)$ and N26 (

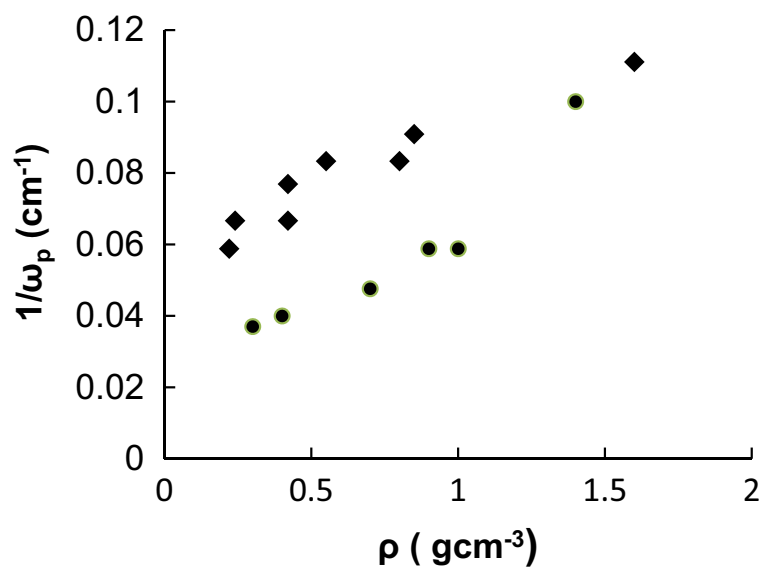

Fig. 16 Variations in $\omega_{\mathrm{p}}^{-1}$ compared with the apparent density of samples B26 ( $)$ and N26

the peak disappeared due to instrumental resolution. The comparison between experimental Raman data (Fig. 16) and SAXS (Fig. 13) shows a direct correlation between " $a$ " and " $\omega_{\mathrm{p}}{ }^{-1}$ " for sintered aerogels. During sintering, we observe that " $\omega_{\mathrm{p}}{ }^{-1}$ " and " $a$ " increase in both sets of aerogels.

The results of SAXS and Raman [11] showed that the size of the aggregates $(\xi)$ decreased, while the size of the particles $\left(a, \omega_{\mathrm{p}}^{-1}\right)$ increased. The interpretation of these data suggests that densification is due to interfacial transformations within aggregates that pull on the network. Densification takes place through the coalescence of several small particles into a larger one. This result is consistent with viscous flow sintering. $D$ appeared to remain constant in the initial phase of the sintering, then tended toward 3. This increase indicates internal densification of the aggregates related to the coalescence of the particles.

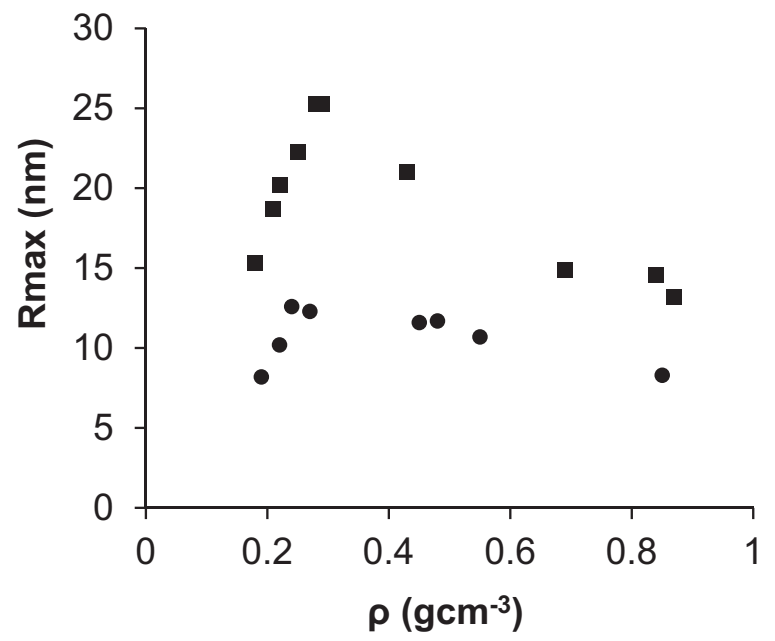

Fig. 17 Changes in Rmax in samples N26 (ם) and B26 (•) versus bulk density

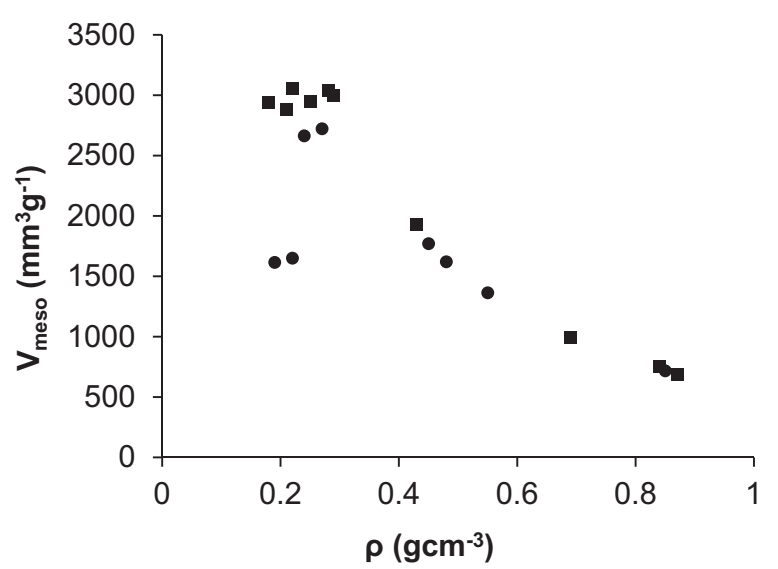

Fig. 18 Changes in mesopore volume of samples N26 (ם) and B26 (๑) versus bulk density

\subsection{Changes in the texture of aerogels}

In the present study, changes in the texture of the silica aerogel texture during sintering were monitored by thermoporometry [32]. In a previous study [21], no micropores were detected in the silica aerogels. Figures 17, 18, and 19 show changes in Rmax, Vmeso, and Vmacro during densification. Rmax is the maximum of the mesopore size distribution on the pore radius scale. Figures 17-19 show the changes in the porous features in two samples, N26 and B26.

The volume of the macropores decreased with an increase in the density. However, the mesoporous volume remained constant up to a density close to $0.3 \mathrm{~g} \mathrm{~cm}^{-3}$ when the macropores disappear. Because the macropores decrease in size, they enter the mesoporous domain. In other words, as they decrease, the macropores partially contribute to the mesopore volume. However, the fact that the mesoporous 


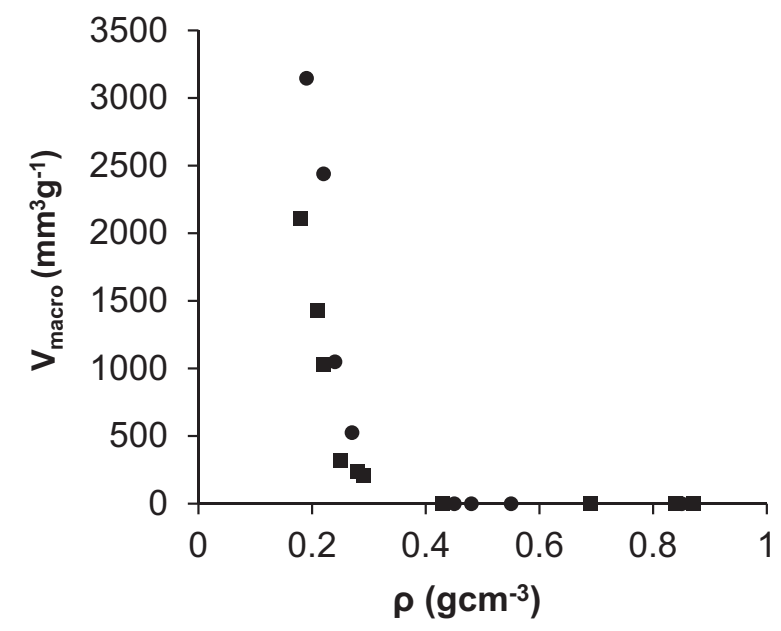

Fig. 19 Changes in the macropore volume of samples N26 (ם) and B26 (O) versus bulk density

volume remained constant also shows that some of the original mesopores disappeared as sintering progressed. The contribution of the original macropores to the mesopores was confirmed by the change in Rmax.

Figures 17-19 show that in the initial period of sintering, the pore volume of the silica aerogels changed in an unexpected way. The mesopore volume remained constant, while Rmax increased. The size of macropores decreased and the macropores became mesopores. A probable explanation is that during the heat treatment, the smaller pores sinter first, as predicted by the viscous flow sintering models [12]. Simultaneously, this local densification takes over the structure and causes narrowing of the macropores. The unexpected behavior of macropores can play an important role in permeability. The ability of partially densified aerogels to be impregnated with active molecules will depend on residual macropores.

During the sintering heat treatments, the microstructure of the aerogel is modified and the mechanical properties are improved $\left(10^{3}-10^{4}\right)$ on the density range [33]. Reinforcement of the material is directly related to the decrease in pore volume [33], but also to structural changes. In the 0.18-0.4 density range, the sintered aerogels are mechanically stronger than non-sintered aerogels of the same bulk density. We thus conclude that heat treatment increased the connectivity or the size of the necks between the particles. In addition to eliminating pores, sintering heat treatment increases network connectivity [34].

\section{Comparison of sintered aerogels with conventional glass}

The silica glass obtained after controlled thermal treatment of an aerogel is dense, transparent and has the same physical properties as conventional glassy silica. Transmission measurements in the UV, near IR and IR spectral ranges revealed the absence of transition metal impurities and confirmed the good optical quality of the sintered aerogel. The most important difference is the high $\mathrm{OH}$ content that can favor crystallization at temperatures above $1200^{\circ} \mathrm{C}$. If necessary, a dehydration heat treatment (halogenation) can be used to completely remove the $\mathrm{OH}$ [5].

It is reported in the literature that glasses made from gels can differ from conventional glasses. Previous work [35, 36] on the preparation of alkaline borosilicate glasses by gel melting (not sintering) showed that the homogeneity of glasses produced from gels is obtained in a much shorter melting time than in the conventional process. However, experimental results on structural relaxation in glasses obtained by sintered gels [37] led to the conclusion that, after the gel has been sintered, there are no significant differences in the field of glassy transition. A SAXS study on the kinetics of phase separation in soda-lime glasses [38] showed that for similar $\mathrm{OH}$ contents, there was no noticeable difference between the phase separation behavior of the gel and the ordinary glass. Brillouin scattering and low frequency Raman scattering [39, 40] revealed slight differences between sintered silica aerogel and silica glass. These differences in sound velocity, hypersonic attenuation, and "peak boson" frequency (middle order characteristic) can also be attributed to the higher $\mathrm{OH}$ content.

Finally, despite the structural differences before sintering, the structure and the properties of the heat-treated gels above the glass transition temperature ( $\mathrm{Tg}$ ) become indistinguishable from those of conventional glasses obtained by quenching, assuming the gel and the glass are of identical composition ( $\mathrm{OH}$ content included).

Another question is whether gel-derived glasses exhibit the same crystallization behavior as ordinary glasses [41]. In contrast to the expected benefit of the sol-gel pathway (its ability to produce glasses with compositions that crystallize normally during quenching), it has been shown that gels tend to crystallize at lower temperatures than conventional glasses. This behavior was again attributed to the high $\mathrm{OH}$ content and the higher specific surface area that could increase crystal nucleation rates [42]. The formation of the glass using the gel method requires heating the gel slowly, then keeping the gel at a temperature close to the glass transition temperature [43].

\section{Conclusion}

The viscous flow sintering model proposed by Scherer is in good agreement with the sintering kinetics of the aerogels studied in this work (fractals or not). It was thus possible to calculate the viscosities of aerogels at different temperatures and to derive the activation energies. The results of these 
calculations are in good agreement with those of conventional vitreous silica provided the high concentration of $\mathrm{OH}$ present in the sintered aerogels is taken into account.

Aerogels are therefore not only precursors for the synthesis of glasses but are also materials with a polymerizable structure, high $\mathrm{OH}$ content, large surface area and high pore volume. Compared to a glass with the same oxide composition, the dried gels have higher structural energies. The surface, the silanol groups and the additional free volume (due to a lower crosslinking density) contribute to this high free energy, and, during the thermal conversion to glass, the gel becomes more strongly connected, while its surface area and its free volume decrease [44]. Gel-derived silica glass has the same physical properties as conventional silica glass. The advantage of the sol-gel route is the low heat treatment temperature and the high purity of the sintered material. The process has been extended to multicomponent glasses in bulk (borosilicate, phosphosilicate, lanthanide-doped glasses, etc.) [44-47]. For optical applications, gradient index glasses and optics without polishing elements have been synthesized [44, 45]. The sol-gel route has also generated new glass matrices for the containment of nuclear waste [46].

Given that glass production is only one end product of this process, new types of materials are also being developed. The intermediate steps of the process make it possible to generate new families of materials, for example by combining polymer synthesis with sol-gel techniques $[9,10]$. These combinations produce hybrid (organic/inorganic) networks in which the organic constituents are not removed by heat treatment and hence participate in network connectivity. Another family of new materials results from the biphasic character of the gel; the porous texture of the gel can be used as a host matrix. The porosity allows the gel to be impregnated with a liquid species. The ability to adjust the pore volume and the potential liquid diversity (monomers, electrolytes, salts in solution, gelling solutions, etc.) extend the possibilities of the sol-gel-glass process to a wide range of silica doped with composite materials and containers. In addition to its technological interest, the sol-gel route also raises certain fundamental problems. Aerogels are ideal materials in that changes in physical properties with respect to the structure can be studied experimentally over the entire porosity range, i.e., from 0 to $99 \%$.

\section{Compliance with ethical standards}

Conflict of interest The authors declare that they have no conflict of interest.

\section{References}

1. Scholze H (1991) Glass: Nature, structure, and properties. Springer-Verlag: New York
2. Zarzycki J (1991) Glasses and the Vitreous State, Cambridge, Solid State Science Series. Cambridge University Press

3. Gottardi V (1982) Proceeding of the First International Workshop on Gels. J Non-Cryst Solids 43:1-230

4. Zarzycki J (1997) Past and present of the sol gel science. J Sol-gel Sci Techn 8:17-22

5. Woignier T, Phalippou J, Prassas M (1990) Glasses from aerogels II. J Mater Sci 25:3118-3126

6. Perrin L, Calas -Etienne S, Faivre A, Phalippou J (2003) Sintering of compressed aerogels.J Non-Cryst Solids 325:223-229

7. Scherer G, Calas S, Sempéré R (1998) Sintering aerogels. J SolGel Sci Techn 13:937-943

8. Vollet DR, Donnati DA, Ibanez Ruiz A, De Castro WC (2003) Structural evolution of aerogels prepared from TEOS sonocatalysis upon heat treatment up to $1100^{\circ} \mathrm{C}$. J Non-Cryst Solids 332:73-79

9. Aegerter M, Leventis N, Koebel M (2011) Aerogels Handbook. Springer, New York, USA

10. Brinker CJ, Scherer GW (1990) Sol-gelscience: the physics and chemistry of sol-gel processing. Academic Press Inc, San Diego, USA

11. Gui J-Y, Zhou B, Zhong Y-H, Du A, Shen J (2011) Fabrication of gradient density SiO2 aerogel. J Sol-Gel Sci Technol 58:385-393

12. Scherer GW (1977) Sintering of low-density glasses: I, Theory. J Am Ceram Soc 60(5-6):236-239

13. Schaeffer W, Keefer KD (1986) Structure of random porous materials: silica aerogel. Phys Rev Lett 56:2199-2202

14. Dietler G, Aubert C, Cannell DS, Wiltzius LP (1986) Gelation of colloidal silica. Phys Rev Lett 57:3117-3120

15. Freltof T, Kjems KJ, Sinha SK (1986) Power-law correlations and finite-size effects in silica particle aggregates studied by smallangle neutron scattering. Phys Rev B 33:269-275

16. Teixera J (1988) Small-angle scattering by fractal systems. J Appl Cryst 21:781-785

17. Pelous J, Sauvajol JL, Woignier T, Vacher R (1990) Low frequency vibrational modes related to texture in silica aerogels. J Phys Fr 51:445-441

18. Duval E, Boukenter A, Champagnon B (1986) Determination of the size of microcrystals in glasses by low frequency Raman scattering. Phys Rev Lett 56:2052-2054

19. Woignier T, Phalippou J (1987) Skeletal density of silica aerogels. J Non-Cryst Solids 93(1):17-21

20. Brun M, Lalemand A, Quinson JF, Eyraud C (1977) A new method for the simultaneous determination of the size and shape of pores: the thermoporometry. Thermochim Acta 21:59-88

21. Pauthe M, Quinson JF, Hdach H, Woignier T, Phalippou J, Scherer GW (1991) Autoclave treatment effect on silica alcogel texture. J Non-Cryst Solids 130:1-7

22. Prassas M, Phalippou J, Zarzycki J (1986) Sintering of monolithic silica aerogels. Science of Ceramic Chemical Processing. In: Hench LL, Ulrich DR, Wiley J eds. Ch. 17, p 237

23. Frenkel J (1945) Viscous flow of crystalline bodies under action of surface tension. J Phys, 9 (USSR) 5:385-391

24. Ristić MM, Milosević SD (2006) Frenkel's Theory of Sintering. Sci Sinter 38:7-11

25. Hetherington G, Jack K, Kennedy J (1964) The viscosity of vitreous silica. J Phys Chem Glass 5(5):130-136

26. Bruckner R (1970) Properties and structure of vitreous silica. J Non-Cryst Solids 5:123-175

27. Emmerling A, Fricke J (1997) Scaling properties and structure of aerogels. J Sol-Gel Sci Tech 8:781-788

28. Woignier T, Phalippou J, Pelous J, Courtens E (1990) Different kinds of fractal structures in silica aerogels. J Non-Cryst Solids 121:198-201

29. Reichenauer G, Scherer GW (2001) Effects upon nitrogen adorption analysis in aerogels. J Coll Interface Sci 236:385-386 
30. Marlière C, Despetis F, Etienne P, Woignier T (2001) Very largescale stucture in sintered silica aerogels as evidenced by AFM and USAXS experiments. J Non-Cryst Solids 285(1-3):148-153

31. Pelous J, Sauvajol JL, Woignier T, Vacher R (1989) The densification of mass fractal aerogels to fused silica: a Raman study of vibrational evolution. Phys A 157:625-629

32. Woignier T, Phalippou J, Quinson JF, Pauthe M, Repellin-Lacroix M, Scherer GW (1994) The sintering of silica aerogels studied by thermoporometry. J Sol-Gel Sci Techn 2:277-281

33. Woignier T, Phalippou J, Hdach H, Larnac G, Pernot F, Scherer GW (1992) Evolution of mechanical properties during the alcogelaerogel-glass process. J Non-Cryst Solids 147-148:672-680

34. Schaeffer DW, Brinker CJ, Richter D, Farago B, Frick B (1990) Dynamics of weakly connected solids: Silica aerogels. Phys Rev Lett 64(19):2316-2319

35. Mukherjee SP (1988) Ultrastructure glasses from sol-gel processes in "Sol gel technology for thin films, fibers, preforms electonics and specially shapes". Noyes, Park Ridge, NJ, p 247-257

36. Konijnendijk WL, Van Duuren M, Groenendijk H (1973) Preparation of homogeneous borosilicate glasses by wet chemical processing. Verres Refract 27(1):11-13

37. Scherer GW, Brinker CJ (1986) Stuctural relaxation in gel-derived glasses. J Non -Cryst Solids 82:191-197

38. Neilson GF, Weinberg MC, Smith GL (1986) Effect of OH content on phase separation behaviour of soda-silica glasses. J Non-Cryst Solids 82:137-142
39. Terki F, Levellut C, Boissier M, Pelous J (1996) Low-frequency dynamics and medium range order in vitreous silica. Phys Rev B 53(5):2411-2418

40. Caponi S, Fontana A, Mattarelli A, Montagna M, Terki F, Woignier T (2004) Influence of thermal treatment in high and low frequency dynamics of silica porous systems. J Non-Cryst Solids 61:345-346

41. Mackenzie JD (1988) Applications of the sol-gel process. J NonCryst Solids 100:162-169

42. Zanotto ED (1992) The formation of unusual glasses. J Non-Cryst Solids 147-148:820-823

43. Uhlmann DR, Weinberg MC, Teowee G (1988) Crystallization of gel-derived glasses. J Non-Cryst Solids 100:154-161

44. James PF (1988) The gel to glass transition: chemical and microstuctural evolution. J Non-Cryst Solids 100:93-114

45. Yamane M, Inami M (1992) Variable refractive index by sol-gel process. J Non-Cryst Solids 147-148:606-613

46. Reynes J, Woignier T, Phalippou J (2001) Permeability measurement in composite aerogels: application to nuclear waste storage. J Non-Cryst Solids 285:323-327

47. Toki M, Miyashita S, Takeuchi T, Kande S, Kochi A (1988) A large-size silica glass produced by a new sol-gel process. J NonCryst Solids 100:479-482 